\title{
MOBILIDADE URBANA SUSTENTÁVEL: PROPOSTA DE UM SISTEMA CICLOVIÁRIO PARA LONDRINA
}

\author{
Caroline Cesário de Castro ${ }^{1}$
}

\author{
Milena Kanashiro²
}

\begin{abstract}
RESUMO
O modal cicloviário está entre as discussões sobre Mobilidade Urbana Sustentável. Esta pesquisa tem como objetivo principal apresentar o processo de projeto de um sistema de ciclovia com um estudo de caso para a cidade de Londrina-PR. A metodologia adotada partiu de uma fundamentação teórica e análise de projetos similares; análise das diretrizes propostas pelo poder público Federal e Municipal; perfil dos deslocamentos dos londrinenses; análise das condicionantes do sítios físico para definição de viabilidade, estruturas existentes de suporte e possibilidades de compatibilidade. A proposta definiu um network ciclável a partir de cinco tipos de ciclovias e simulações para quatro tipos diferentes de cruzamentos, compatíveis para integrar-se às estruturas de terminais de transporte urbano coletivo além de bicicletários. Esta pesquisa tem uma contribuição efetiva, demonstrando a possibilidade de novas alternativas de mobilidade sustentável que podem ser adaptadas no contexto das cidades brasileiras.
\end{abstract}

PALAVRAS-CHAVE: Sistema de ciclovias; Mobilidade Urbana Sustentável; Cidades sustentáveis.

\section{SUSTAINABLE URBAN MOBILITY: PROPOSAL OF A SYSTEM FOR LONDRINA CICLOVIÁRIO}

\begin{abstract}
On Sustainable Urban Mobility the modal share of cycling is increasing. This research aims to present the process of designing a system of cycling to a case study: the city of Londrina-Pr. The methodology adopted was: theoretical framework and analysis of similar projects; analysis of the guidelines proposed by the Federal government and Municipal; profile of displacements of Londrina; analyze the landform in order to define feasibility and existing structures and possibilities of compatibility. The proposal defined a cycling network from five types and simulations for four different types of crosses, compatible to integrate into the structure of urban public transport terminals. This research has an effective contribution demonstrating the possibility of new alternatives for sustainable mobility that can be adapted in the context of Brazilian cities.
\end{abstract}

1 Arquiteta e Urbanista, Universidade Estadual de Londrina, Londrina, Paraná, Brasil, carol_cesario@hotmail.com

${ }_{2}$ Arquiteta e Urbanista, Universidade Estadual de Londrina, Departamento de Arquitetura e Urbanismo, Londrina, Paraná, Brasil.milena@uel.br 


\section{MOVILIDAD URBANA SOSTENIBLE: PROPUESTA DE UN SISTEMA PARA LONDRINA CICLOVIÁRIO}

\section{RESUMEN}

El ciclo modal es entre los debates sobre movilidad urbana sostenible. Esta investigación tiene como principal objetivo presentar el proceso de diseño de un sistema de bicisendas a Londrina-PR. La metodología adoptada se apartó de una fundamentación teórica y el análisis de proyectos similares; Análisis de los lineamientos propuestos por federales y Gobierno Municipal; Perfil de desplazamientos de londrinenses; Análisis del relieve de la ciudad para la definición de la viabilidad, las estructuras de apoyo y posibilidades de compatibilidad. La propuesta define una red ciclista de cinco tipos de simulaciones para cuatro diferentes tipos de cruces, compatibles para integrar las estructuras de los terminales de transporte colectivo urbano además de bicicletas y ciclovías. Esta investigación tiene una contribución efectiva, demostrando la posibilidad de nuevas alternativas de movilidad sostenible que se pueden adaptar en el contexto de ciudades brasileñas.

PALABRAS CLAVE: Sistema de carriles para bicicletas; Movilidad urbana sustentable; Ciudades sostenibles.

\section{INTRODUÇÃO}

O desenvolvimento e crescimento desenfreado das cidades têm causado grandes mudanças, alterando gradativamente a realidade urbana. Problemas quanto aos deslocamentos são um dos exemplos evidentes a respeito dessas transformações devido ao aumento significativo da frota. Tal processo reflete no espaço urbano o contínuo aumento das vias e um espalhamento do tecido nas cidades que, nas cidades brasileiras, as vias para automóveis ocupam em média $70 \%$ do espaço público e transportam apenas de $20 \%$ a $40 \%$ dos habitantes (Born apud Instituto de Energia e Meio Ambiente, 2010). Essa estratégia em favorecimento do uso e de soluções para o automóvel tem ocasionado os principais problemas de mobilidade urbana. Mancini (2011) acrescenta algumas consequências indiretas como: saturação da capacidade viária, altos níveis de emissões de substâncias e ruídos poluentes, altos índices de mortalidade, reforço da desigualdade social, bem como ressalta o aumento de deficiência física causada pelo número de acidentes.

Em contraponto à essa maneira de organização das cidades, ao longo da década de 1990, segundo Costa (1999), houve um conjunto de preocupações para 
criação de cidades ambientalmente desejáveis discutidas pela Comissão das Comunidades Européias entre as quais a criação de cidades compactas reduziriam deslocamentos e promoveriam uma melhor qualidade de vida. Espacialmente a utilização de áreas de usos mistos, limitação de crescimento da cidade, promoção do preenchimento dos vazios urbanos, contribuiriam para uma menor distância entre o percurso casa-trabalho e por conseqüência, incentivariam o uso de transportes mais eficientes para pequenos percursos. Nesse sentido, para Campos (2006), na discussão de cidades sustentáveis a mobilidade tem o enfoque tanto na adequação da oferta de transporte ao contexto socioeconômico e na ênfase da qualidade ambiental.

No Brasil, o Ministério das Cidades, por meio da Secretaria Nacional de Transportes e da Mobilidade Urbana reforça a necessidade de um conjunto de políticas de transporte e circulação que visa proporcionar o acesso amplo e democrático ao espaço urbano, por meio da priorização dos modos de transporte coletivo e não-motorizados de maneira efetiva, socialmente inclusiva e ecologicamente sustentável (ANTP, 2003b; Ministério das Cidades, 2006a, SeMOB, 2007).

Entre as chamadas "viagens sustentáveis" Mancini (2011) considera aquelas geradas por modos pequenos de poluentes, como a caminhada e o uso da bicicleta, para pequenas distâncias, e o transporte coletivo para distâncias maiores. Silveira (2010) aponta também que a bicicleta cumpre um papel de socialização: é acessível as pessoas de qualquer faixa de renda, contribui para a integração da população com o ambiente construído, cria espaços acessíveis e, quando há infraestrutura cicloviária adequada integra com outros modais de transporte.

No Brasil, o PlanMob (2007), define diretrizes para a elaboração de propostas considerando tipologias de ciclovias para possibilitar a implantação de soluções viáveis ao nosso contexto: ciclovia segregada em terreno limpo; ciclovia segregada junto à via; ciclofaixas; ciclovia segregada em calçada e passeio compartilhado. Podem ser citados os exemplos de Porto Alegre e Curitiba como cidades que possuem um Plano Cicloviário integrado ao transporte público e outras 
que tem apresentado investimento de infraestrutura de ciclovias como Santo André, Florianópolis, Blumenau, Pomerode, Recife, Sorocaba, Fortaleza.

A cidade de Londrina, localizada no norte do Estado do Paraná-Brasil, atualmente possui pouco mais de meio milhão de habitantes (IBGE, 2014) e uma infraestrutura viária com três opções básicas de transporte na cidade: o transporte público coletivo, realizado por ônibus, o automóvel e as motocicletas. Segundo o DENATRAN (Departamento de Trânsito Nacional), Londrina possuía em 2010 uma frota de automóveis de 175.116 veículos; já em Maio de 2015, a frota registrada na cidade de automóveis foi de 226.923, um aumento de quase $30 \%$ em apenas cinco anos.

Assim, esta pesquisa tem como objetivo principal apresentar um processo de análise e proposição de um network cicloviário considerando a conexão bairroscentro bem como integrados aos terminais de transporte público como contribuição à discussão para tornar uma cidade mais acessível e sustentável.

\section{METODOLOGIA E ANÁLISE}

Para elaborar um projeto compatível com a cidade de Londrina, foram adotados os seguintes procedimentos: a) levantamento bibliográfico; b) análise de estudos e projetos similares; c) coleta de dados e pesquisas existentes da cidade de Londrina - relatório de acidentes, questionários realizados com ciclistas e projetos realizados; d) análise: do sítio físico para verificação de declividade de vias, possíveis locais de integração entre modais de transporte; análise de dimensionamento e compatibilidade de vias. Tais procedimentos deram subsídios para a definição da proposta.

A primeira etapa, levantamento bibliográfico, consistiu em pesquisas e conceitos abordados na temática do projeto por meio de estudos existentes. A análise de projetos foi realizada a partir das similaridades, compreendendo os pontos de vista, abordagem e aplicação de métodos de pesquisa. As cidades de Bogotá, Santiago, Porto Alegre e Florianópolis foram definidas para estudos e 
análises de suas características urbanas e de suas ciclovias. Abaixo, a Tabela 1 apresenta as características de cada uma delas:

Tabela 1. Características das cidades estudadas que apresentam ciclovias.

\begin{tabular}{|c|c|c|c|c|}
\hline $\begin{array}{c}\text { Características/ } \\
\text { Cidades }\end{array}$ & Bogotá & Santiago & Porto Alegre & Florianópolis \\
\hline População & 8.493 .675 & 5.428 .590 & $\begin{array}{c}1.409 .939 \text { (IBGE } \\
2010)\end{array}$ & $\begin{array}{c}421.203 \text { (IBGE } \\
2010)\end{array}$ \\
\hline Sistema viário & $\begin{array}{l}\text { Transmilênio } \\
\text { (VLP). }\end{array}$ & $\begin{array}{l}\text { TransSantiago } \\
\text { (ônibus+metrô) }\end{array}$ & $\begin{array}{l}\text { Ônibus + metrô } \\
\text { (ainda não } \\
\text { circulando) }\end{array}$ & $\begin{array}{l}\text { Ônibus (vias com } \\
\text { caixa reduzida) }\end{array}$ \\
\hline $\begin{array}{l}\text { Perfil dos } \\
\text { ciclistas e das } \\
\text { viagens }\end{array}$ & $\begin{array}{c}35 \% \text { estudo; } \\
31 \% \text { trabalho; } \\
14 \% \text { esportes; } \\
16 \% \text { outros; } \\
4 \% \text { recreação. }\end{array}$ & $\begin{array}{l}\text { Idade média } 35 \\
\text { anos, viagem com } \\
\text { duração } 20 \mathrm{~min}, 5 \mathrm{x} \\
\text { mais homens } \\
\text { utilizam. }\end{array}$ & $\begin{array}{l}\text { Usuários de baixa } \\
\text { renda, distancia } \\
\text { entre } 2 \text { e } 3 \mathrm{~km} \text {, } \\
\text { algumas acima de } \\
9 \mathrm{~km} .\end{array}$ & $\begin{array}{c}\text { Pouca mulher } \\
\text { utiliza, maioria } \\
(73 \%) \text { entre } 13 \text { e } \\
35 \text { anos, } \\
\text { trabalhadores } \\
(56 \%) \text {, renda } 1 \text { e } \\
3 \text { salários } \\
\text { mínimos }(59 \%)\end{array}$ \\
\hline $\begin{array}{l}\text { Divisão pelo } \\
\text { modal de } \\
\text { transportes }\end{array}$ & - & $\begin{array}{c}\text { A pé: } 37 \% ; \\
\text { Bicicleta: } 3 \% \text {; } \\
\text { Transporte } \\
\text { privado: } 20 \% \text {; } \\
\text { Transporte } \\
\text { Público: } 33 \% \text {; } \\
\text { Outros: } 5 \% \text {. }\end{array}$ & $\begin{array}{c}\text { A pé: } 23 \% ; \\
\text { Bicicleta: } 1 \% \text {; } \\
\text { Privado (automóvel } \\
\text { e taxi): } 36 \% \text {; } \\
\text { Público (ônibus e } \\
\text { lotações): } 36 \% \text {, } \\
\text { Outros: } 4 \% \text {. }\end{array}$ & $\begin{array}{c}\text { Automóvel } \\
\text { particular } 73 \% \text {; } \\
\text { transporte } \\
\text { coletivo } 14 \% ; \\
\text { bicicleta } 2 \% \text {, } \\
\text { outros } 11 \% .\end{array}$ \\
\hline $\begin{array}{l}\text { Itens } \\
\text { considerados } \\
\text { para a } \\
\text { localização das } \\
\text { ciclovias }\end{array}$ & $\begin{array}{l}\text { Vias potenciais: } \\
\text { viabilidade } \\
\text { técnica } 43 \% ; \\
\text { adaptabilidade } \\
22 \% \text {; qualidade } \\
\text { ambiental e } \\
\text { espacial } 20 \% ; \\
\text { valorização } \\
\text { social } 15 \%\end{array}$ & $\begin{array}{l}\text { Mapas feitos pelos } \\
\text { ciclistas com } \\
\text { origens e destinos; } \\
\text { identificação de } \\
\text { vias perigosas. }\end{array}$ & $\begin{array}{l}\text { Demanda atual, } \\
\text { demanda futura, } \\
\text { estatísticas de } \\
\text { acidentes com } \\
\text { ciclistas, restrições } \\
\text { topográficas, fluxo } \\
\text { de veículos, } \\
\text { característica do } \\
\text { sistema viário. }\end{array}$ & $\begin{array}{c}\text { Fluxo de } \\
\text { veículos, } \\
\text { presença de fluxo } \\
\text { de carga pesada; } \\
\text { dimensão das } \\
\text { caixas das vias. }\end{array}$ \\
\hline $\begin{array}{l}\text { Tipos de } \\
\text { ciclovias }\end{array}$ & $\begin{array}{c}\text { Ciclovias } \\
\text { bidirecionais e } \\
\text { ciclofaixas }\end{array}$ & $\begin{array}{c}\text { Ciclovia } \\
\text { bidirecional e } \\
\text { unidirecional em } \\
\text { pista segregada; } \\
\text { Ciclofaixa; Ciclovia } \\
\text { compartilhada com } \\
\text { passeio para } \\
\text { pedestres. }\end{array}$ & $\begin{array}{c}\text { Ciclovia } \\
\text { unidirecional } \\
\text { localizada na } \\
\text { calçada, na rua e } \\
\text { no canteiro central; } \\
\text { Ciclovia bidirecional } \\
\text { localizada na } \\
\text { calçada, na rua e } \\
\text { no canteiro central; } \\
\text { Cruzamento com } \\
\text { tratamento } \\
\text { especial. }\end{array}$ & $\begin{array}{c}\text { Via } \\
\text { compartilhada; } \\
\text { falsa ciclofaixa; } \\
\text { ciclovia } \\
\text { unidirecional; } \\
\text { ciclovia } \\
\text { bidirecional; } \\
\text { ciclofaixa } \\
\text { unidirecional e } \\
\text { bidirecional. }\end{array}$ \\
\hline
\end{tabular}




\begin{tabular}{|c|c|c|c|c|}
\hline $\begin{array}{c}\text { Características/ } \\
\text { Cidades }\end{array}$ & Bogotá & Santiago & Porto Alegre & Florianópolis \\
\hline $\begin{array}{l}\text { Modo de } \\
\text { integração com } \\
\text { ouros modais }\end{array}$ & $\begin{array}{c}\text { Integrada ao } \\
\text { Transmilenio } \\
\text { (VLP) }\end{array}$ & $\begin{array}{c}\text { Integrada ao } \\
\text { transporte público } \\
\text { urbano }\end{array}$ & $\begin{array}{c}\text { Integrada ao } \\
\text { transporte público } \\
\text { urbano }\end{array}$ & $\begin{array}{c}\text { Integrada ao } \\
\text { transporte público } \\
\text { urbano }\end{array}$ \\
\hline $\begin{array}{l}\text { Locais para } \\
\text { implantação dos } \\
\text { estacionamentos } \\
\text { (paraciclos e } \\
\text { bicicletários) }\end{array}$ & $\begin{array}{l}\text { Terminais do } \\
\text { Transmilênio }\end{array}$ & Estações do metrô & $\begin{array}{l}\text { Polos geradores de } \\
\text { viagens e nos } \\
\text { terminais de } \\
\text { transporte coletivo. }\end{array}$ & $\begin{array}{l}\text { Shoppings, } \\
\text { terminais de } \\
\text { ônibus e } \\
\text { rodoviário, } \\
\text { universidades, } \\
\text { supermercados, } \\
\text { hospitais. }\end{array}$ \\
\hline $\begin{array}{l}\text { Abrangência do } \\
\text { projeto }\end{array}$ & $\begin{array}{l}\text { Projetado para } \\
\text { conectar-se com } \\
\text { municípios } \\
\text { vizinhos }\end{array}$ & $\begin{array}{l}\text { Abrange a cidade } \\
\text { de Santiago. }\end{array}$ & $\begin{array}{l}\text { Abrange a cidade } \\
\text { de Porto Alegre. }\end{array}$ & $\begin{array}{l}\text { Abrange a área } \\
\text { central de } \\
\text { Florianópolis }\end{array}$ \\
\hline $\begin{array}{l}\text { Medidas para } \\
\text { estimular o uso }\end{array}$ & $\begin{array}{l}\text { Divulgação das } \\
\text { informações do } \\
\text { projeto e suas } \\
\text { intenções }\end{array}$ & $\begin{array}{l}\text { Conscientização, } \\
\text { divulgação de } \\
\text { informações. }\end{array}$ & $\begin{array}{l}\text { Divulgação do } \\
\text { Plano Diretor } \\
\text { Cicloviário, } \\
\text { orientação aos } \\
\text { motoristas, ciclistas } \\
\text { e pedestres. }\end{array}$ & $\begin{array}{l}\text { Realização de } \\
\text { seminários } \\
\text { regionais do } \\
\text { Programa } \\
\text { Cidades Amigas } \\
\text { da Bicicleta; } \\
\text { campanhas } \\
\text { educativas. }\end{array}$ \\
\hline
\end{tabular}

Fonte: DAS AUTORAS, 2011.

$\mathrm{Na}$ etapa de levantamento e análise de dados, foram obtidos informações e documentos junto ao IPPUL - Instituto de Pesquisa e Planejamento Urbano de Londrina, quanto aos locais de acidentes com ciclistas na cidade registrados de janeiro a setembro de 2010; questionários aplicados a 500 ciclistas e 500 pessoas que utilizam de outro modo de transporte em 2006; e fluxo de ciclistas durante todo um dia e as principais vias utilizadas por eles.

Quanto aos acidentes, o levantamento do IPPUL mostrou que os principais locais onde ocorrem mais acidentes envolvendo ciclistas são nos cruzamentos; neste período ocorreram 80 acidentes. A respeito do fluxo de ciclistas, esses se deslocam pelas vias de maior fluxo na cidade, como a Av. Dez de Dezembro, Av. Arthur Thomas, Av. Rio Branco e Av. Henrique Mansano.

O questionário aplicado foi analisado para identificar o perfil do ciclista londrinense e dos usuários de outros modais de transporte, a fim de que se 
proponha um sistema de ciclovia que atenda às necessidades da população (Tabela 2).

Tabela 2. Resultado do questionário com ciclistas e usuários de outros modos de transporte.

\begin{tabular}{|c|c|c|c|c|c|}
\hline Perguntas & / Entrevistados & Ciclistas & $\begin{array}{l}\text { Usuários de Veículos } \\
\text { particulares }\end{array}$ & $\begin{array}{l}\text { Usuários de } \\
\text { Ônibus }\end{array}$ & Pedestres \\
\hline \multirow{3}{*}{ Sexo } & Masculino & $88,4 \%$ & $73,5 \%$ & $53,5 \%$ & $65,7 \%$ \\
\hline & Feminino & $11,6 \%$ & $26,5 \%$ & $46,5 \%$ & $34,3 \%$ \\
\hline & Até 18 anos & $11,8 \%$ & $7 \%$ & $14,5 \%$ & $27,1 \%$ \\
\hline \multirow{4}{*}{$\begin{array}{l}\text { Faixa } \\
\text { Etária }\end{array}$} & 19 a 35 anos & $58 \%$ & $53,5 \%$ & $65 \%$ & $51,4 \%$ \\
\hline & 36 a 50 anos & $23,2 \%$ & $29,6 \%$ & $16,5 \%$ & $12,9 \%$ \\
\hline & 51 a 65 anos & $6,8 \%$ & $7 \%$ & $3 \%$ & $7,1 \%$ \\
\hline & Acima de 65 anos & $0,2 \%$ & $3 \%$ & $1 \%$ & $1,4 \%$ \\
\hline \multirow{4}{*}{$\begin{array}{c}\text { Motivo da } \\
\text { viagem }\end{array}$} & Trabalho & $97,6 \%$ & $94,3 \%$ & $96,5 \%$ & $85,7 \%$ \\
\hline & Estudo & $2,4 \%$ & $5,7 \%$ & $3,5 \%$ & $14,3 \%$ \\
\hline & Até $\mathrm{R} \$ 300$ & $4,6 \%$ & $2,6 \%$ & $4,5 \%$ & $7,1 \%$ \\
\hline & $\mathrm{R} \$ 301$ a $\mathrm{R} \$ 500$ & $23,4 \%$ & $10,4 \%$ & $23 \%$ & $14,3 \%$ \\
\hline \multirow[t]{5}{*}{ Renda } & $\mathrm{R} \$ 501$ a $\mathrm{R} \$ 700$ & $30 \%$ & $13,9 \%$ & $24 \%$ & $22,9 \%$ \\
\hline & $\mathrm{R} \$ 701$ a $\mathrm{R} \$ 1000$ & $25,8 \%$ & $32,6 \%$ & $28,5 \%$ & $37,1 \%$ \\
\hline & Acima de $R \$ 1000$ & $16,2 \%$ & $40,4 \%$ & $20 \%$ & $18,6 \%$ \\
\hline & Até $0,5 \mathrm{~km}$ & $1,4 \%$ & $0,9 \%$ & $0 \%$ & $17,1 \%$ \\
\hline & 0,5 a $2 \mathrm{~km}$ & $17,8 \%$ & $13,9 \%$ & $2,5 \%$ & $54,3 \%$ \\
\hline \multirow[t]{5}{*}{ Distância } & 2 a $5 \mathrm{~km}$ & $37 \%$ & $30,9 \%$ & $17,5 \%$ & $25,7 \%$ \\
\hline & 5 a $10 \mathrm{~km}$ & $30,6 \%$ & $27 \%$ & $45,5 \%$ & $0 \%$ \\
\hline & Acima de $10 \mathrm{~km}$ & $13,2 \%$ & $27,4 \%$ & $34,5 \%$ & $2,9 \%$ \\
\hline & Até $15 \mathrm{~min}$ & $28,4 \%$ & $53,9 \%$ & $10 \%$ & $52,9 \%$ \\
\hline & 15 a $30 \mathrm{~min}$ & $48,2 \%$ & $34,8 \%$ & $39,5 \%$ & $37,1 \%$ \\
\hline \multirow{5}{*}{$\begin{array}{l}\text { Tempo de } \\
\text { viagem }\end{array}$} & $30 \min$ a $1 \mathrm{~h}$ & $19,4 \%$ & $5,7 \%$ & $44 \%$ & $7,1 \%$ \\
\hline & $1 \mathrm{a} 2 \mathrm{~h}$ & $4 \%$ & $0 \%$ & $6,5 \%$ & $0 \%$ \\
\hline & Acima de $2 \mathrm{~h}$ & $0 \%$ & $5,7 \%$ & $0 \%$ & $2,9 \%$ \\
\hline & Saudável & $14 \%$ & $8,3 \%$ & $0 \%$ & $41,4 \%$ \\
\hline & Barato & $54,4 \%$ & $13 \%$ & $54 \%$ & $37,1 \%$ \\
\hline \multirow[t]{3}{*}{ Motivo } & Seguro & $0,4 \%$ & $0,4 \%$ & $8,5 \%$ & $2,9 \%$ \\
\hline & Confortável & $0,2 \%$ & $23 \%$ & $5,5 \%$ & $1,4 \%$ \\
\hline & Rápido & $31 \%$ & $55,2 \%$ & $32 \%$ & $17,1 \%$ \\
\hline
\end{tabular}

Fonte: IPPUL, 2006. 
Por meio do questionário, pode-se identificar que a maioria dos usuários de bicicleta é do sexo masculino, adultos e utilizam como meio de transporte para o deslocamento ao trabalho, com percursos até $10 \mathrm{~km}$.

No levantamento das propostas existentes para a cidade, buscou-se junto ao IPPUL a localização das ciclovias existentes na cidade e as ciclovias que estão sendo propostas. No entanto, as ciclovias apresentadas pelo órgão municipal são desconexas, não possuem projetos específicos para cruzamentos e não conectam pontos importantes da cidade.

As estratégias para a definição do projeto cicloviário foram subsidiados pela análise dos projetos existentes, pela avaliação das condicionantes do sitio físico e de infraestrutura local. Os itens apresentados foram avaliados e comparados ao contexto da cidade, de forma a contribuir nas decisões de adequação do sistema de ciclovias a uma cidade com uma infraestrutura totalmente projetada ao transporte individual motorizado. Desta forma são listadas, a seguir, as principais diretrizes para a elaboração do projeto:

- Adequar o sistema cicloviário a partir dos usuários de bicicleta (perfil dos ciclistas da população);

- Conhecer como são divididos os deslocamentos urbanos e planejar ciclovias que sejam acessíveis, seguras e estimulem seu uso;

- Definir as rotas das ciclovias a partir das prioridades determinantes no processo de projeto do sistema como: relevo, fluxos de veículos, fluxos de pedestres, vias utilizadas atualmente pelos ciclistas, principais pontos de acidentes envolvendo ciclistas;

- Estudar cada tipo de ciclovia e suas particularidades e propor rotas que possuam infraestrutura adequada;

- Integrar as ciclovias aos terminais de transporte público;

- Propor estacionamentos em locais estratégicos;

A partir da análise de todas as informações obtidas foram determinadas as principais diretrizes: ciclovias contínuas; conexão de ciclovias dos bairros ao centro; ciclovias a cada aproximadamente $750 \mathrm{~m}$; uso de locais atrativos como rotas de 


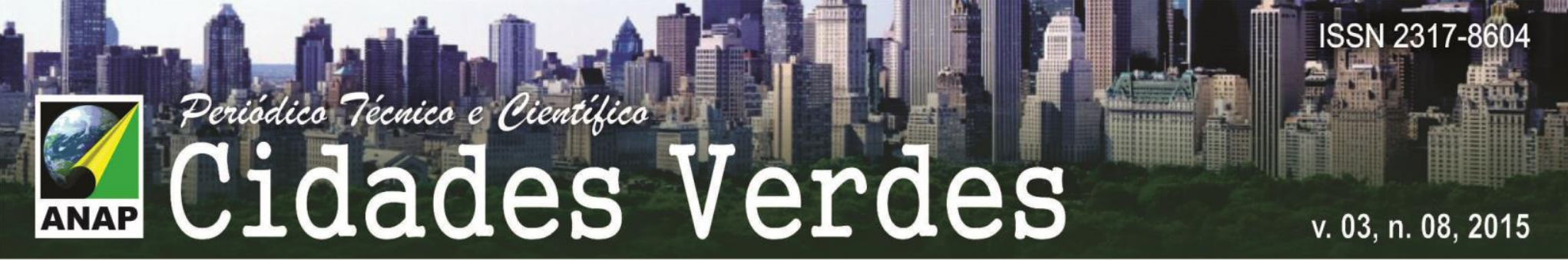

passagem; optar por vias que comportem ciclovias ou ciclofaixas; vias com pouca declividade, sempre que possível; e optar vias seguras.

\section{UM PROJETO PARA UMA CIDADE CICLÁVEL}

A cidade de Londrina conta atualmente com aproximadamente 13 quilômetros de ciclovias implantadas em poucas vias da cidade e sem conexão entre elas (IPPUL, 2011). A bicicleta poderia ser uma opção de transporte sustentável a ser utilizado pela população por meio de um projeto adequado, conectando os bairros aos pontos de trabalho e também aos terminais de transporte coletivo.

Primeiramente, foram escolhidas as vias onde seriam propostas as ciclovias, a partir de critérios de avaliação do relevo e de infraestrutura. Como referencial, utilizou-se as inclinações adequadas indicadas no PlanMob (2007), disponibilizado pelo Ministério das Cidades: para desnível de até $2 \mathrm{~m}$, inclinação máxima de $10 \%$; para $4 \mathrm{~m}, 5 \%$; e para $6 \mathrm{~m}, 3,3 \%$ de inclinação. A Figura 01 traz a síntese do network proposto para a cidade. 


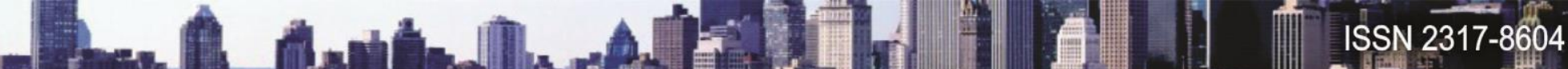

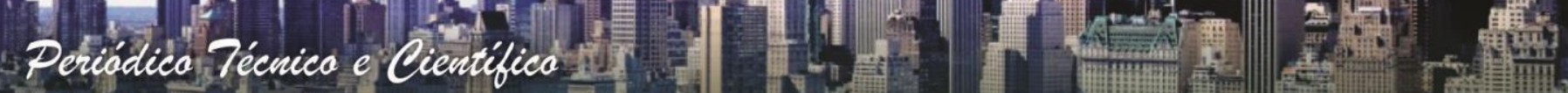 Cidades Verdes}

Figura 1. Proposta do network ciclável.

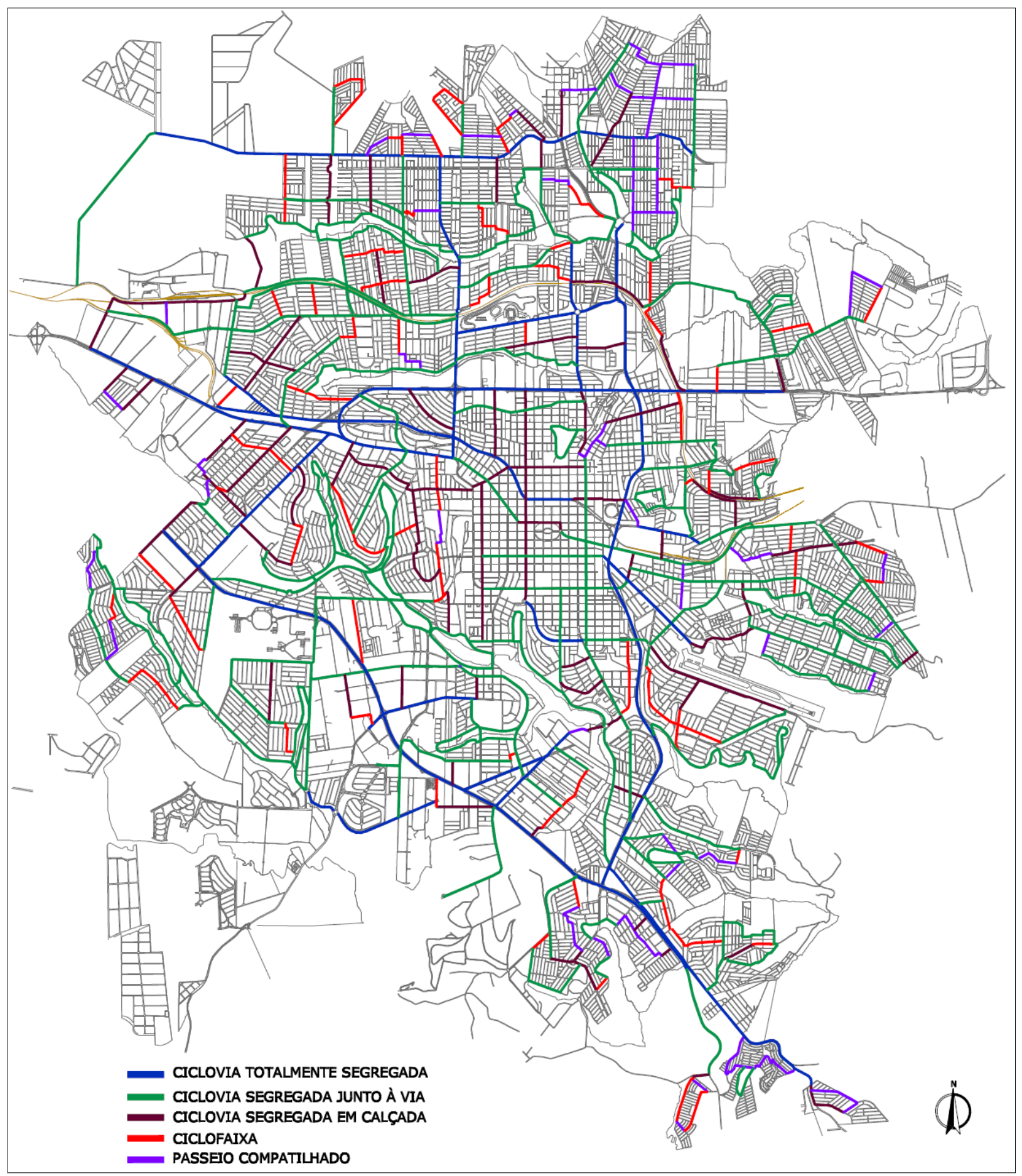

Fonte: AUTORAL, 2011.

A determinação da tipologia de ciclovia adotada no projeto está diretamente ligada às características das vias pré-definidas. Fatores como segurança e classificação viária também contribuíram para a decisão. Optou-se, primeiramente, 
por dividir em quatro categorias: Vias Cicloviárias Principais, Vias Cicloviárias Distribuidoras, Vias Cicloviárias Secundárias e Vias Cicloviárias Recreativas. Com base nos tipos de ciclovia propostos pelo PlanMob (2007) a única opção não adotada no projeto foi o Passeio Separado com Espaço para Circulação de Bicicletas. A extensão total de ciclovia propostas para o projeto foram $399,75 \mathrm{~km}$.

Figura 2. Exemplo de ciclovia totalmente segregada.

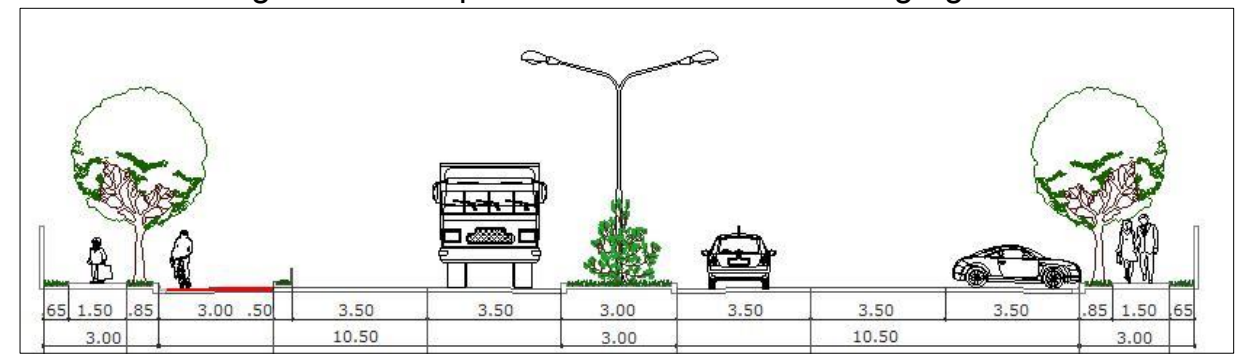

Fonte: Autoral (2011).

Figura 3. Exemplo de ciclovia segregada junto à via.

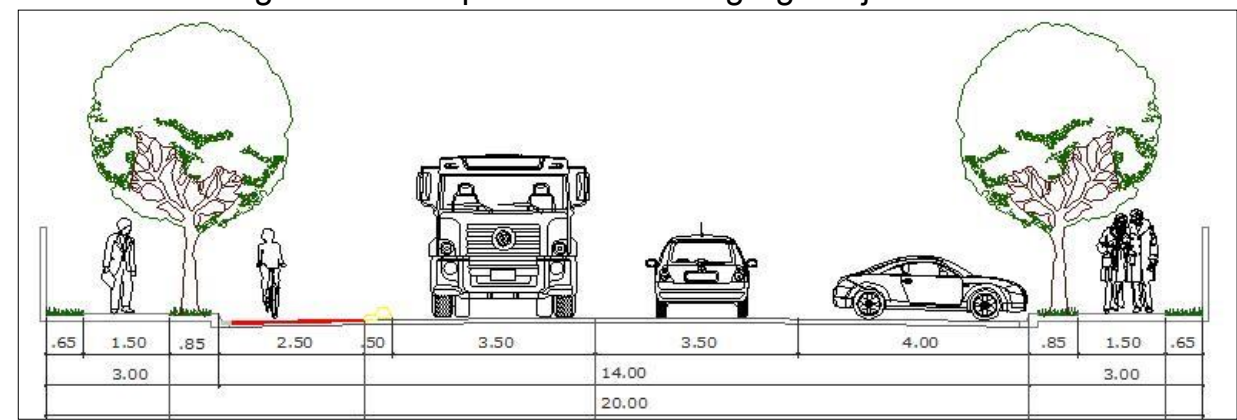

Fonte: Autoral (2011).

Figura 4. Exemplo de ciclovia segregada junto à calçada.

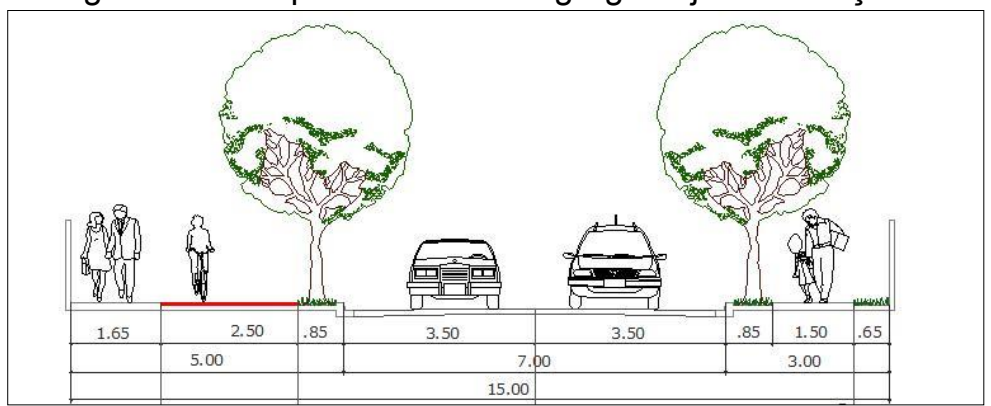

Fonte: Autoral (2011). 


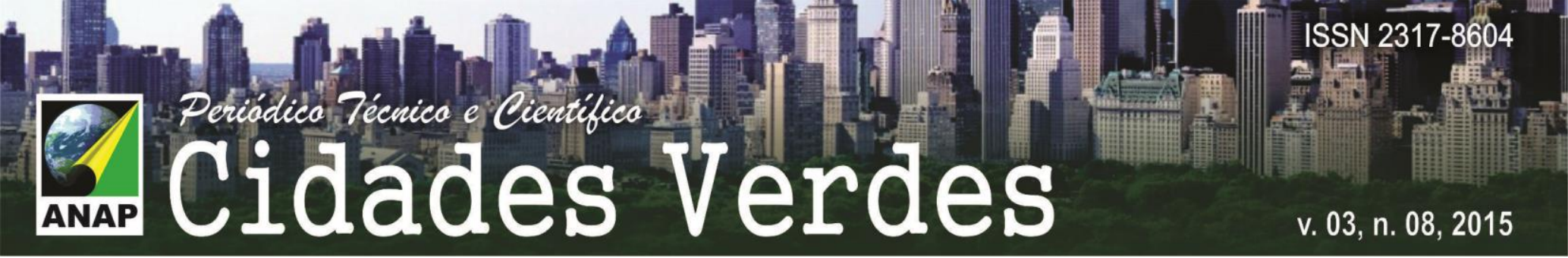

Figura 5. Exemplo de ciclofaixa de mão dupla

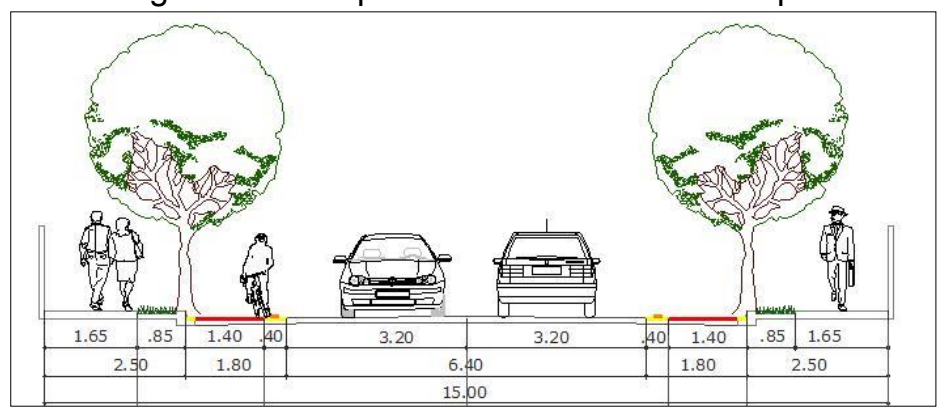

Fonte: Autoral (2011).

Figura 6. Exemplo de passeio compartilhado.

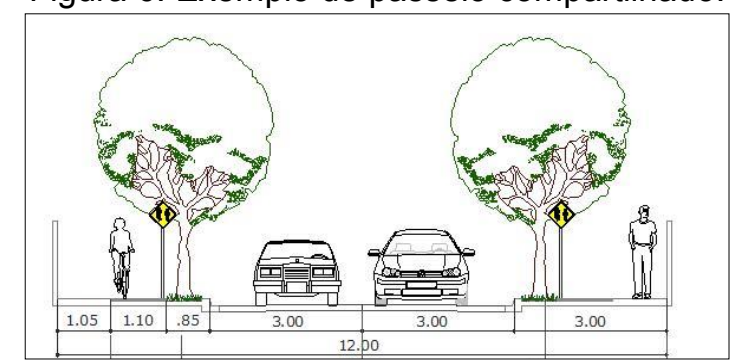

Fonte: Autoral (2011).

Dentro um sistema cicloviário, os cruzamentos são os locais considerados menos seguros e com maior índice de acidente. Foram propostos projetos de cruzamentos adequados para cada tipo de encontro de ciclovia identificado, num total de 289 cruzamentos, divididos em: rotatórias - com um total de 45 e cruzamentos em "+", em "T" e em "Y" - com um total de 244.

Figura 7. Exemplo de cruzamento em rotatória.

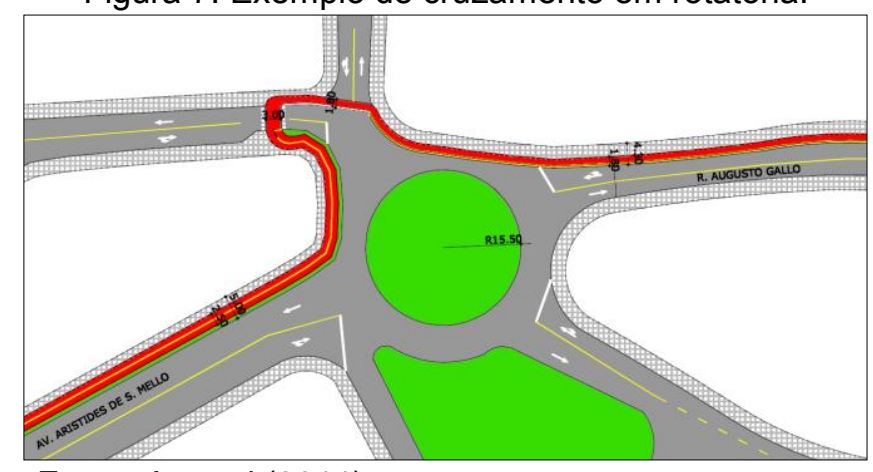

Fonte: Autoral (2011) 
Figura 8. Exemplo de cruzamento em "Y".

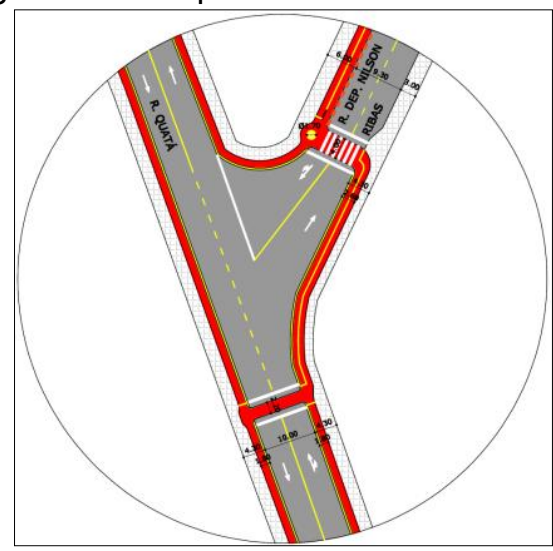

Fonte: Autoral (2011).

Para a complementação do projeto, elaborou-se duas propostas de paraciclos e duas de bicicletários. Os paraciclos oferecem menor grau de segurança, no entanto, são mais econômicos, ocupam um menor espaço físico, podem ser instalados em locais abertos ou mesmo em áreas privadas para uso de funcionários de uma empresa. No estudo de caso foram propostos, para sua instalação, locais próximos às entradas de hospitais, postos de saúde, supermercados e órgãos públicos.

Por outro lado, os bicicletários apesar de proporcionar um maior controle necessitam de um funcionário para atendimento aos ciclistas e, geralmente tem um custo mais elevado para sua instalação e manutenção. Para Londrina, os dois estacionamentos propostos possuem 40 e 25 vagas, sendo o último concebido de forma a ser móvel, construído com estrutura metálica. Tais apoios ao sistema cicloviário poderão ser instalados em locais geradores de fluxos como shoppings, terminais de transporte coletivo, próximos aos locais onde há eventos na cidade, supermercados e universidades.

\section{CONSIDERAÇÕES FINAIS}

O presente trabalho teve como objetivo demostrar o processo de análise e de proposição de um sistema de ciclovias para a cidade de Londrina, integrado aos terminais urbanos da cidade. Desta forma acredita-se que este modal mais 
sustentável possa ser inserido com alternativa de transporte a ser utilizada pela população.

A proposição elaborada após todas as análises dos dados define um sistema de ciclovia com projetos de cruzamentos e ciclovias específicas integradas à infraestrutura existente na conexão de bairros e de áreas centrais. A inclusão de bicicletários e paraciclos é necessária para o funcionamento do sistema.

Esse processo de inclusão do uso da bicicleta avaliando o sistema viário existente pode ser possível em nossas cidades brasileiras. No entanto, a reflexão de tornar nossas cidades mais sutentáveis dependem de uma política pública efetiva e integrada em todas as esferas Federais e Municipais para redirecionar a concepção de organização de nossas cidades.

\section{REFERÊNCIAS}

ANTP. Associação Nacional de Transporte Público. Disponível em: <http//www.antp.org.br> Acesso em: 15 de março de 2014.

BIANCO, S. L. O Papel da Bicicleta para a Mobilidade Urbana e a Inclusão Social. São Paulo, SP: ANTP. 2003.

BRASIL. Instituto de Energia e Meio Ambiente. A Bicicleta e as Cidades: como inserir a bicicleta na política de Mobilidade Urbana. Brasília, DF: 2010.

BORN, Liane. Vá de Bicicleta. Revista Vida Simples, Edição 68, ano 6, oํ 07, p.26, 2008.

CAMPOS, V. B. G. Uma Visão da Mobilidade Urbana Sustentável. Revista dos Transportes Públicos n 110. Associação Nacional dos Transportes Públicos. 2006.

COSTA, H. S. d. M. Desenvolvimento Sustentável: Uma Contradição de Termos?. Revista Brasileira de Estudos Urbanos Regionais, Número 2: 55 - 71. 1999.

COSTA, M. d. S. Um Índice de Mobilidade Urbana Sustentável. Tese (Doutorado). Departamento de Transportes, Escola de Engenharia de São Carlos, Universidade de São Paulo, São Carlos, SP: 2008.

DENATRAN. Departamento Nacional de Transporte. Disponível em: $<$ http//www.denatran.gov.br/frotas. Acesso em 02 de julho de 2014.

GOMIDE, A.d.A. Transporte Urbano e Inclusão Social: Elementos para Políticas Públicas. Texto para discussão n`960. Instituto de Pesquisa Econômica Aplicada. Brasília, DF: 2003.

IBGE. Instituto Brasileiro de Geografia e Estatística. Disponível em:

$<$ http://www.ibge.gov.br/home/> Acesso em 22 de junho de 2014.

IPPUL. Instituto de Pesquisa e Planejamento Urbano de Londrina. Questionário sobre deslocamentos da população. Londrina, PR: 2006. 
LEI 12.587/2012. Disponível em: http://www.planalto.gov.br/ccivil_03/_Ato20112014/2012/Lei/L12587>. Acesso em 20 de junho de 2014.

MANCINI, M. T. Planejamento Urbano baseado em Cenários de Mobilidade Sustentável. Dissertação (Mestrado). Escola de Engenharia de São Carlos da Universidade de São Paulo. São Carlos, SP: 2011.

PLANO DIRETOR CICLOVIÁRIO INTEGRADO DE PORTO ALEGRE. Disponível em: $<$ http.www.bikedrops.wordpress.com/plano-cicloviario-porto-alegre/>. Acessado em: 20 de junho de 2014.

PREFEITURA DE LONDRINA. Disponível em: <http//www.1.londrina.pr.gov.br/>. Acesso em: 21 de junho de 2014.

PROYECTO CHILE BICENTENARI - Plan Maestro de Ciclorutas. Disponível em:

<http://www.plataformaurbana.cl/archive/2009/06/17/proyecto-chile-bicentenario/> Acesso em: 18 de junho de 2014.

ROCHA, A. C. B. Gerenciamento da Mobilidade: Experiências em Bogotá, Londres e alternativas pós-modernas. Pluris 2006 - Congresso Luso Brasileiro para o planejamento urbano, regional, integrado e sustentável. Portugal: 2006.

SEMOB. Secretaria Nacional de Transporte e da Mobilidade Urbana. Caderno de referência para elaboração de Plano de Mobilidade por Bicicleta nas Cidades, PlanMob. Brasília, DF: 2007.

SEMOB. Secretaria Nacional de Transporte e da Mobilidade Urbana. Caderno 2 - Construindo a Cidade Acessível. Brasília, DF: 2006.

SILVEIRA, M. O. Mobilidade Sustentável: A Bicicleta como um meio de transporte integrado. Dissertação (Mestrado). Universidade Estadual do Rio de Janeiro, RJ: 2010. 